\title{
ANALYSIS AND DESIGN OF RAFT FONDATION
}

\author{
Zia-abe Deen. S. Punekar ${ }^{1}$, M H Kolhar ${ }^{2}$, Anjum Algur ${ }^{3}$, Kushappa M K \\ ${ }^{1}$ Professor, Research centre Civil Engg Dept, SIET Vijayapur, Karnataka, India \\ ${ }^{2}$ Associate Professor, Research centre Civil Engg Dept, SIET Vijayapur, Karnataka, India \\ ${ }^{3}$ Associate Professor, Research centre Civil Engg Dept, SIET Vijayapur, Karnataka, India \\ ${ }^{4}$ Assistant Professor, Research centre Civil Engg Dept, SIET Vijayapur, Karnataka, India
}

\begin{abstract}
In Recent Era due to enhanced aesthetic construction we couldn't provide the regular spacing of the column so like we couldn't provide the Isolated footing or combined footing everywhere in every construction, hence it is very common nowadays in the market to provide the Raft footing so it helps in reducing the cost, effort of excavation and prevents sliding of adjacent footing. In this study a 12-storey building having conventional slab has been analyzed using Etabs-13 and Safe-V12 for the parameters like moment, Punching shear and deflection of the footing. The Multistory Model will be imported from ETABS to Safe for the analysis and design of the Raft footing.
\end{abstract}

Keywords: Raft Foundation, SAFE-V12, Response Spectrum Analysis, Punching Shear, and Detailing.

\section{INTRODUCTION}

An earthquake is a manifestation of the rapid release of stress in the form of waves during the process of brittle rupture of rock. Earthquakes are the natural disasters of a generally unpredictable nature. Nowadays, high-rise buildings are the symbols of a modernized living standard because of the population growth. Among them, earthquake disasters are not limited to structural damage and injury/death of people under collapsed structures. A foundation, the lowest part of a structure, is in direct contact with ground and located below the ground level. It transmits all the loads from super-structure to the supporting soil. So, foundation design for an earthquake resistance is one of the most important parts to be considered in the structural analysis and design. For foundations of such high rise building, normally raft foundation, pile foundation or piledraft foundation are used. The raft will be used for economical consideration. The raft foundation is a kind of combined footing that may cover the entire area under the structure supporting several columns in one rigid body.

\subsection{Raft Footing}

The raft will be used for economical consideration. The raft foundation is a kind of combined footing that may cover the entire area under the structure supporting several columns in one rigid body. Raft foundations (sometimes known as Mat Foundations) are a large concrete slab which can support a number of columns and walls. The slab is spread out under the entire building or at least a large part of it which lowers the contact pressure compared to the traditionally used strip or trench footings.

\section{OBJECTIVES}

In this study, the seismic performance of Raft footing will be investigated through Response spectrum analysis.
$>$ To study the Dynamic performance of Raft footing subjected various loadings.

$>$ To study the behavior of the structure for the parameters like Moments, Punching Shear and deflection in SAFE

$>$ Design of the Raft foundation and detailing the same.

\section{METHODOLOGY}

The following methodology is used to achieve the above defined objectives.

$>$ In ETABS 9.7.4 Story building has been analyzed using Response spectrum method.

$>$ Exporting the axial loads at the base of the column to the SAFE V12.FZK text format.

$>$ Modeling the raft foundation (Concrete area) in SAFE V12. And assigning the actual material properties.

$>$ Strips to be drawn both in X \& Y direction @ an interval of $1 \mathrm{ft}$ keeping the strip width of $0.5 \mathrm{ft}$.

$>$ Then its required to satisfy both One-way shear \& Punching Shear.

$>$ Analyze the model for the axial Loads derived from the ETABS-9.7.

$>$ Footing should be analyzed for envelope combinations which includes all the load combinations and design of the Raft foundation and detailing the same.

Table-1: Building Description

\begin{tabular}{|ll|l|}
\hline $\begin{array}{l}\text { Number of } \\
\text { storey- }\end{array}$ & 12 - storey \\
\hline $\begin{array}{l}\text { Thickness of } \\
\text { slab }\end{array}$ & $150 \mathrm{~mm}$ \\
\hline Beams & $\begin{array}{l}\text { B200X450M25, } \\
\text { B300X450M25, B300X600M25, } \\
\text { B300X900M25, B300X750M25 }\end{array}$ \\
\hline Columns & $\begin{array}{l}\text { C300X1000M30, C650X1000M30, } \\
\text { C800DiaM45 }\end{array}$ \\
\hline
\end{tabular}




\begin{tabular}{|l|l|}
\hline Walls & $\begin{array}{l}\text { Wall200XVaries, Wall300XVaries, } \\
\text { Wall400XVaries, Wall550XVaries }\end{array}$ \\
\hline $\begin{array}{l}\text { Steel and } \\
\text { Concrete }\end{array}$ & Fe500 and $\mathrm{M}_{25}, \mathrm{M}_{30}$ \\
\hline
\end{tabular}

Table-2: Design Loads and Seismic Parameters

\begin{tabular}{|l|l|}
\hline Live load & $3 \mathrm{kN} / \mathrm{m}^{2}$ \\
\hline Floor finish & $1.5 \mathrm{kN} / \mathrm{m}^{2}$ \\
\hline Wall Loads & $17.5 \mathrm{KN} / \mathrm{m}^{2}, 12 \mathrm{KN} / \mathrm{m}^{2}$ \\
\hline Zone & $\mathrm{IV}$ \\
\hline Importance Factor & $\mathrm{I}=1$ \\
\hline $\begin{array}{l}\text { Response Reduction } \\
\text { factor }\end{array}$ & $\mathrm{R}=5(\mathrm{SMRF})$ \\
\hline SBC & $300 \mathrm{KN} / \mathrm{m}^{2}$ \\
\hline Codes Used & $\begin{array}{l}\text { IS-456-2000,IS-1893- } \\
2002, S P-16\end{array}$ \\
\hline
\end{tabular}

\section{BUILDING MODELS}

The most important step in the Seismic Analysis of a structure is to create an appropriate mathematical model that will adequately represent its stiffness, mass distribution and energy dissipation so that its response to earthquake could be predicted with sufficient accuracy. The frames have been modeled and analyzed using software ETABS-9.7. Beams and columns are modeled as frame elements with centerline dimensions. Supports at the base are assumed to be fixed. And raft foundation is modeled in Safe-V12 as a slab element and SAFE provides an immensely capable yet easyto-use program for structural designers, providing the only tool necessary for the modeling, analysis, design, and detailing of concrete slab systems and foundations. User Interface SAFE offers a single user interface to perform: Modeling, Analysis, Design, Detailing and Reporting.

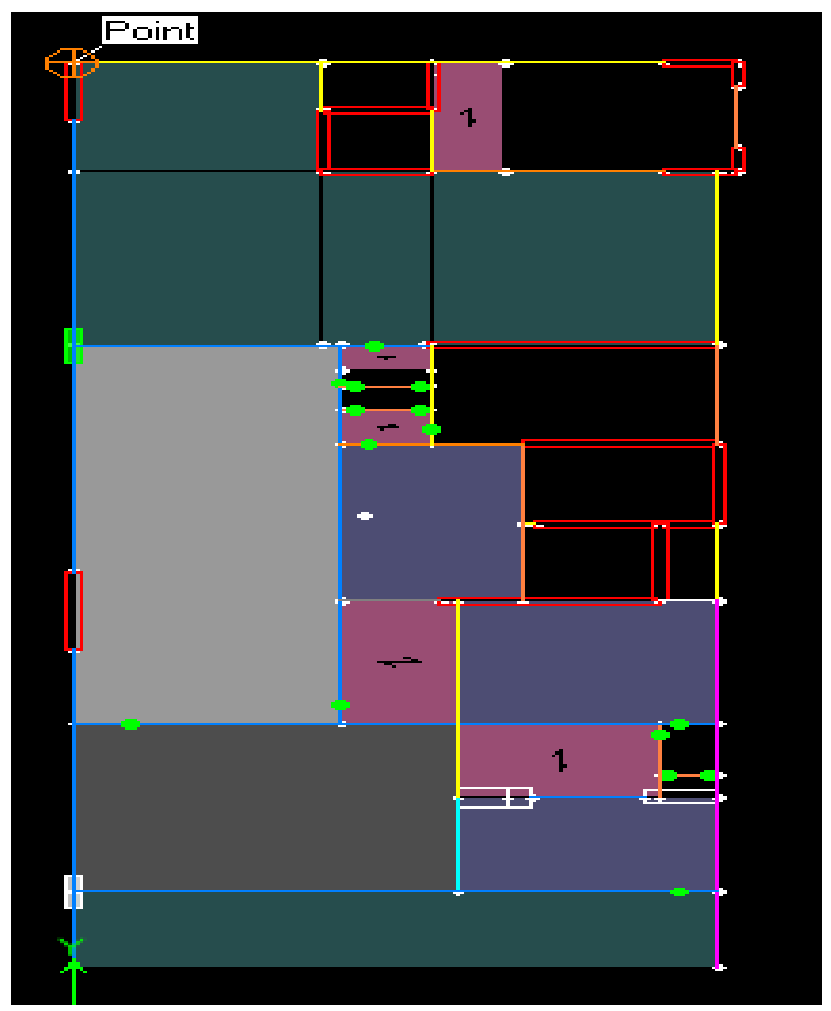

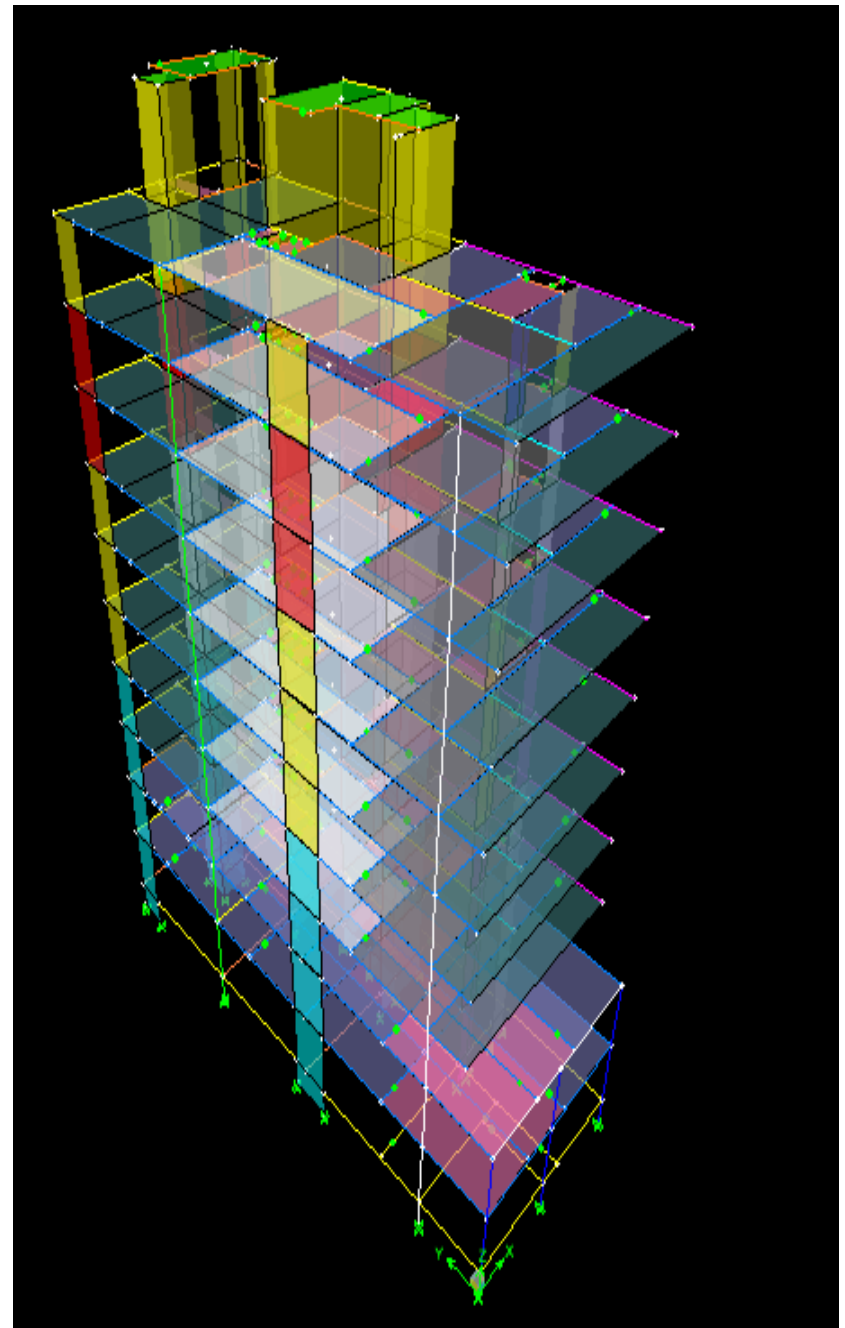

Fig- 1: Plan and 3D view of building

\section{RESULT AND DISCUSSION}

The selected frame models are analyzed using (Dynamic) Response Spectrum analysis. The results obtained from this analysis are such as Axial Loads from foundation level are exported from Etabs-9.7 and then imported in SAFE-V12. And modeled and analyzed in SAFE to study the behavior of the structure for the parameters like Moments, Punching Shear and deflection in SAFE and designed the Raft foundation and detailing the same.

\subsection{Moments}

Layer-B (Grid- A) Moment= 1043.07Kn-m, (from SAFE), $\mathrm{M}_{\mathrm{u}} / \mathrm{bD}^{2}=1.287 \mathrm{Pt}=0.316 \%$ Ast $=2844 \mathrm{~mm}^{2}$

From Software same strip Ast $=2500 \mathrm{~mm}^{2}$. 


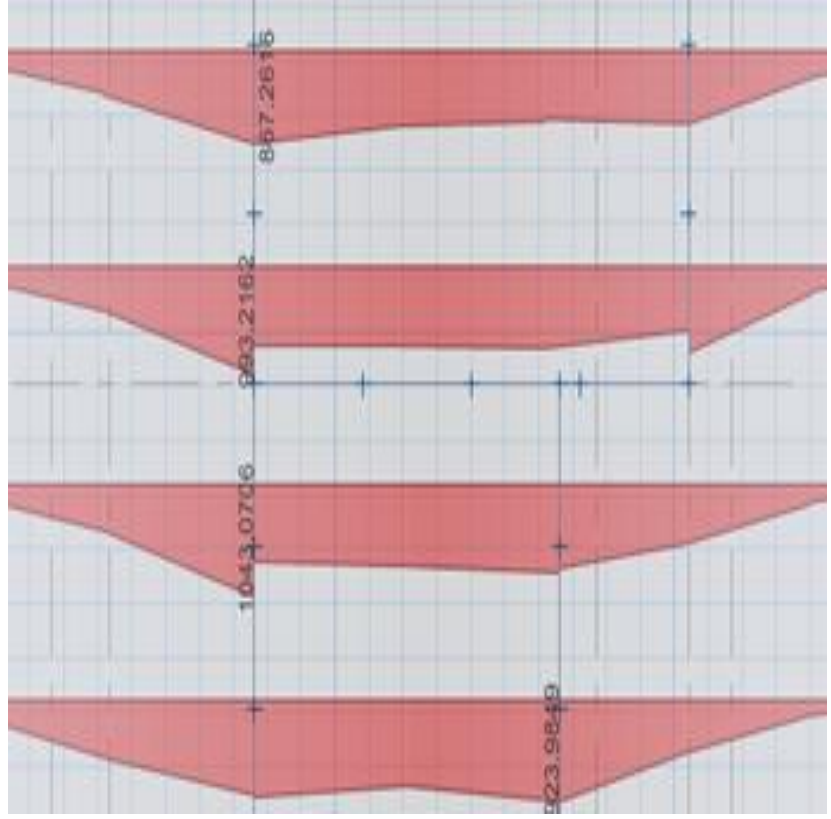

Fig- 2(a): Moments on horizontal strip

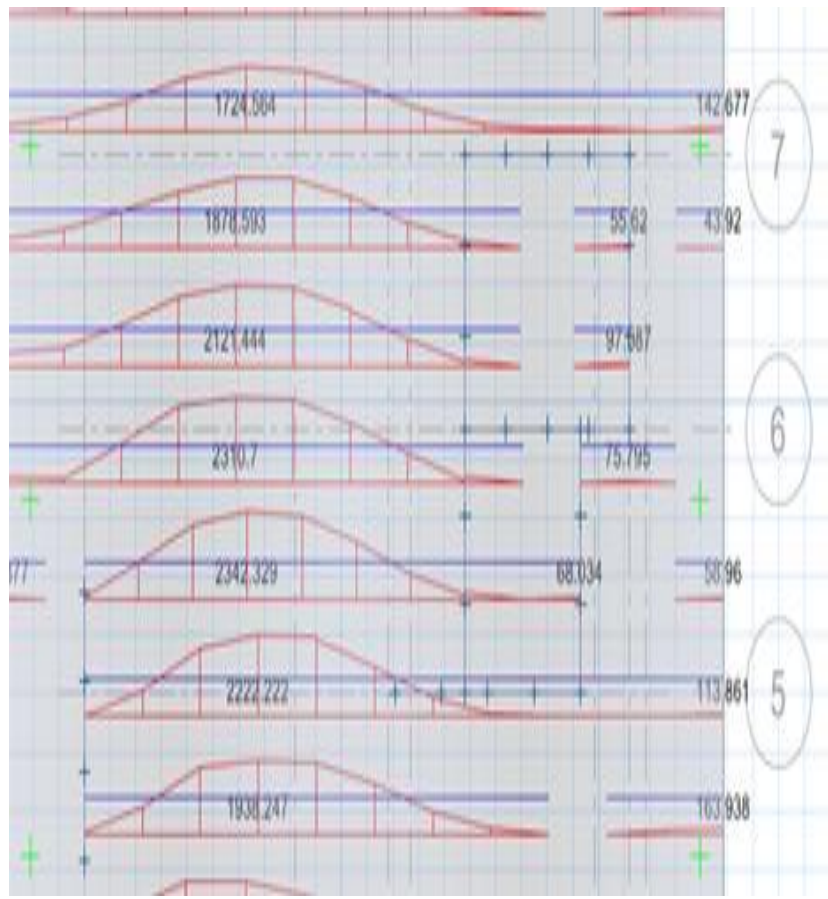

Fig- 2(b): Area of steel on horizontal strip

From the Above figures we can observe that the Area of steel obtained from the moment given from the Safe for the Envelope combination is same as the Area of steel obtained from the strips. So we can conclude that the design process in SAFE is for the Envelope combination.

\subsection{Punching Shear}

Here in this case we can observe that the Punching shear or the other name is Two-way shear will be displayed for smaller column or the columns assigned as line element. Because the in larger column there is no chances of punching the slab/footing at a single point. The load will be converted as linear load.
And in this case the image has been attached to show that the punching stress is lesser than the allowable stress. Hence we know that to satisfy two way shear or punching shear $\tau_{\mathrm{v}}<\tau_{\mathrm{c}}$ i.e $0.1237<1.25$. Hence punching shear is satisfied.

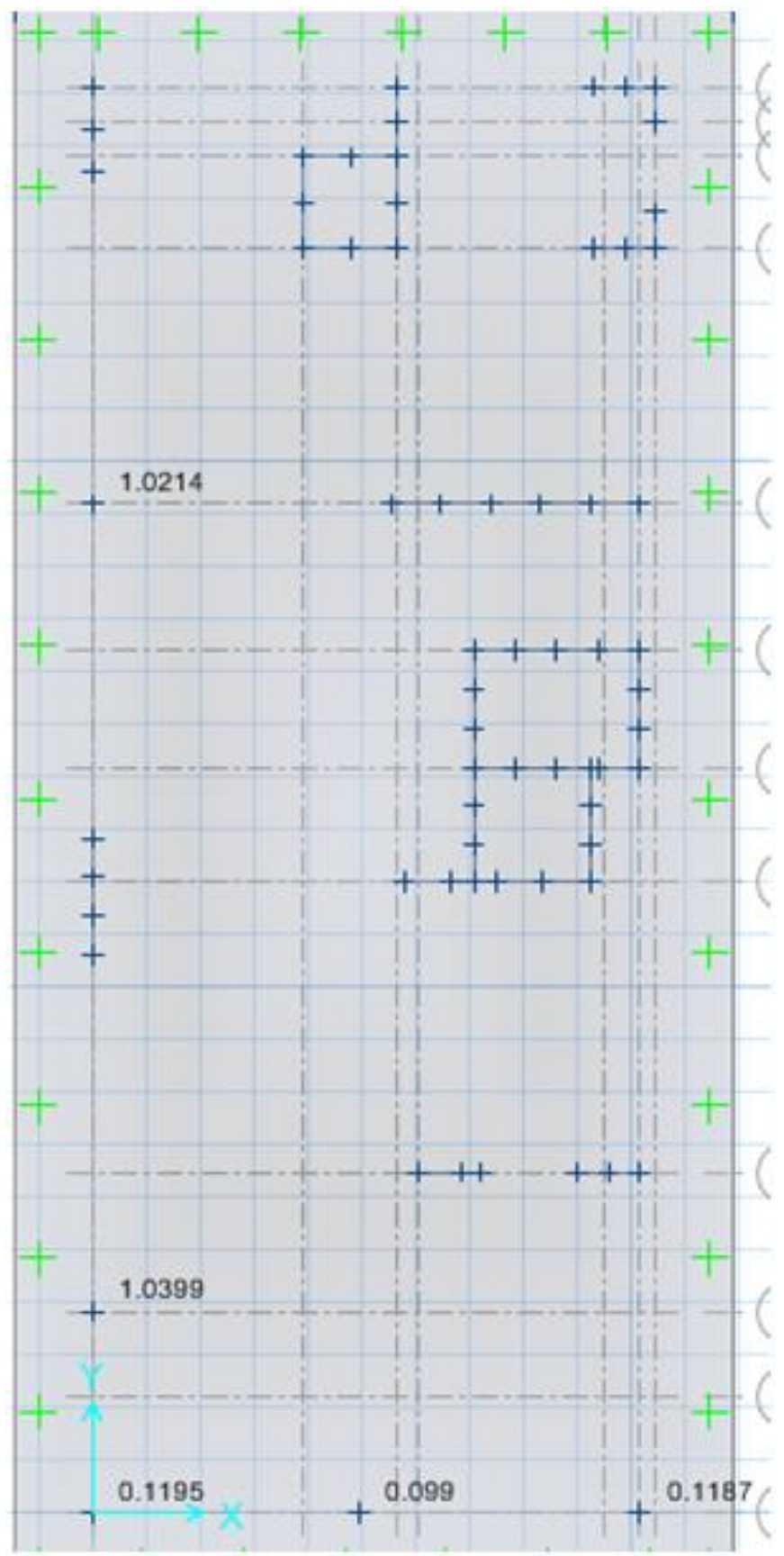

Fig- 3: Punching shear 


\subsection{Deflection}

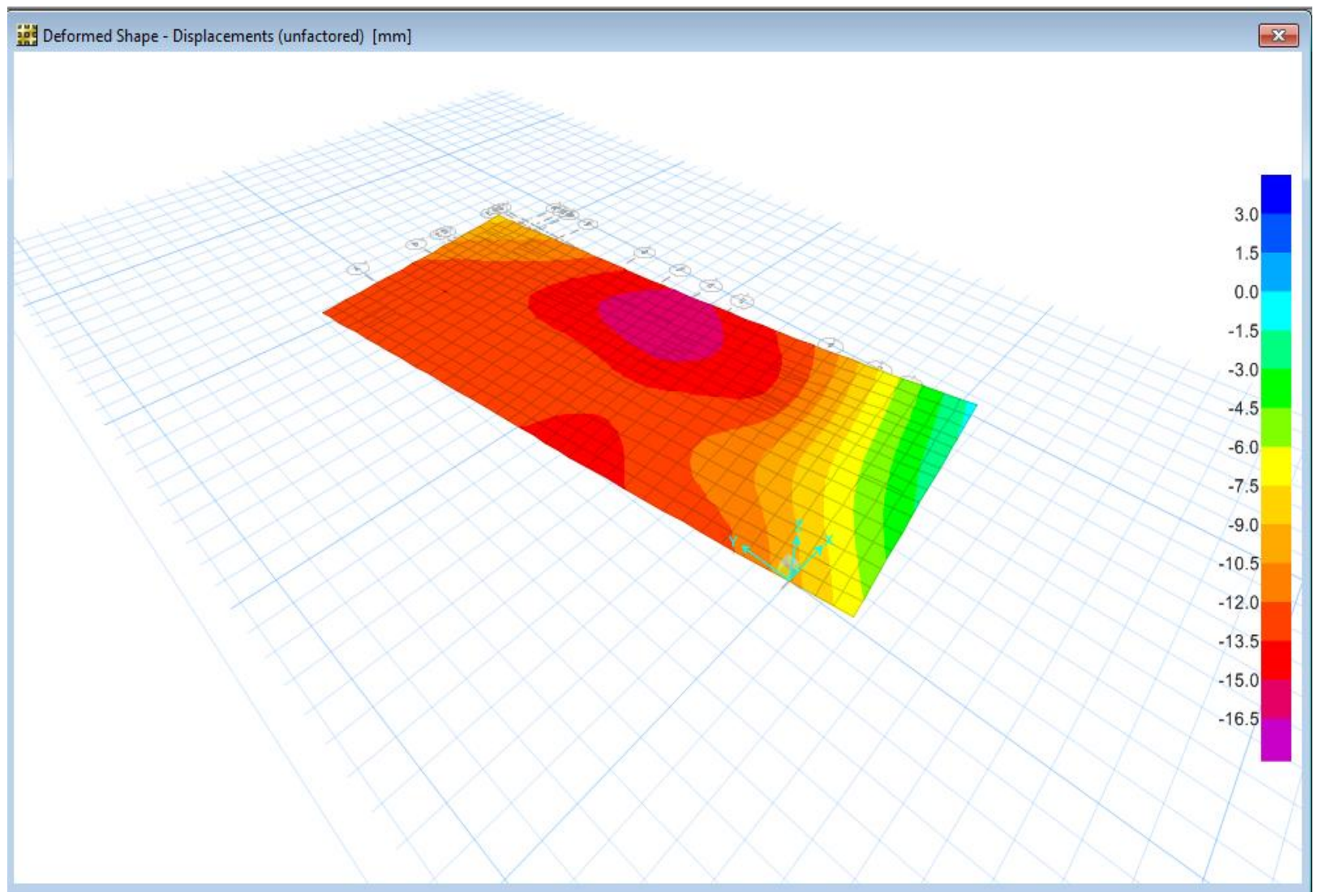

Fig- 4: Deflection

Even though the Raft is on Grade we can expect a slight deflection in the footing. In this we can observe that the deflection of $-16.5 \mathrm{~mm}$ for this larger footing. Negative indicates the hogging deflection.

\subsection{Design and Detailing}

Detailing is done using the area of steel obtained from the SAFE. Detailing will be like Top \& Bottom reinforcement and again it will be like $\mathrm{X}$ direction \& $\mathrm{Y}$ direction reinforcement.

First layer has been provided through and through T16@150c/c both ways in general. And second layer is provided only where ever it is required. 


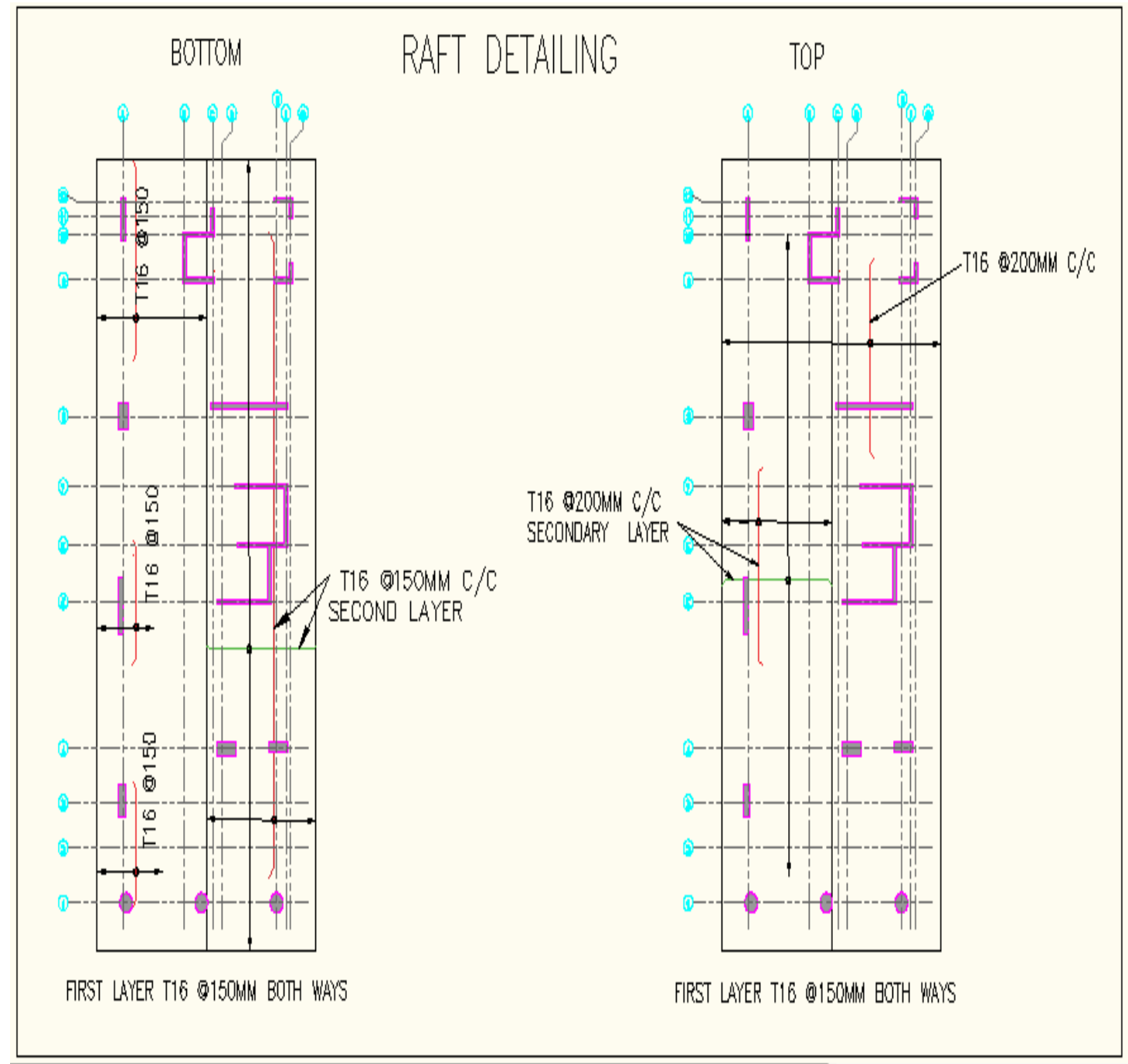

Fig-5: Detailing of Raft Foundation

\section{CONCLUSION}

In this study we can conclude that the Raft footing is analyzed and designed for the envelope combination. That will be the critical combination, obviously for one of the dynamic combinations.

$>$ Moment: From the above study it has been concluded that the area of steel obtained from the moment given from the safe for the envelope combination is same as the area of steel obtained from the strips. So we can conclude that the design process in SAFE is for the envelope combination.

$>$ Punching Shear: It has been also concluded that the mat/raft foundation is safe against punching shear or two way shear i.e. the punching shear ratio is less than 1.

$>$ Deflection: From above study we can also observe that there will be a slight hogging deflection in the raft footing but it will not affect the building and also within the limit.

$>$ Detailing \& Casting: is quite simple compared to isolated footings. Excavation will be in one go and the pouring of concrete will be at a time this leads to saving in both the cost and time.

\section{SCOPE FOR THE FUTURE STUDY}

$>$ We can compare the RAFT and ISOLATED footings for the same building to know the difference in terms of cost.

$>$ We can Analyze and design the Raft Foundation for Time-History Analysis.

$>$ This study can further extended design the Raft or Mat with pile.

\section{REFERENCES}

[1]. THU ZAR AUNG1, DR. KAY THWE TUN, "Parametric Study on Foundation of Regular High-Rise R.C Building under Seismic Load" International journal scientific engineering and technology research, ISSN 23198885 Vol.03, Issue.10 May-2014, Pages: 2089-2095.

[2]. Jay P. Chaliyawala, Hitesh K.Dhameliya,Hiten L. Kheni, "A REVIEW OF PERAMETRIC STUDY OF RAFT FOUNDATION" International journal of Advance Engineering and Research Development, Volume 1, Issue 12, December -2014 
[3]. NithyaChandran J, AbhilashRajan, Soni Syed, "Seismic analysis of building with underground stories considering soil structure interactions" International Journal of Emerging Technology and Advanced Engineering,Website:www.ijetae.com (ISSN 2250-2459, ISO 9001:2008 Certified Journal, Volume 4, Issue 11, November 2014)

[4]. Haytham Adnan Sadeq Mohammed SaleemTaha, "Structural Design of Raft Foundation" Qatar University College of Engineering (Course: Design Of Reinforced Concrete Structures)

[5]. SagarSatishTayade, Mukund M. Mahajan, "Foundation in Refilled Soil" International Journal of Innovative Research in Science, Engineering and Technology, Volume 3, Special Issue 4, April 2014

[6]. IS 456-2000, "Plain and reinforced concrete-code of practice", bureau of Indian standards, new delhi

[7]. IS 875 (Part-I,II,III):1987, "code of practice for design loads for buildings and structures"

[8]. IS 1893 (Part-I):2002, "Criteria for Earthquake resistant design of structures, general provisions for buildings

[9]. SP-16 "Design Aids for Reinforced concrete to IS-4561978.

[10]. ETABS-9.7 Manuals and Tutorials

[11]. SAFE-V12 Manuals and Tutorials

[12]. www. Wikipedia/Raft Foundation.com

\section{BIOGRAPHIES}

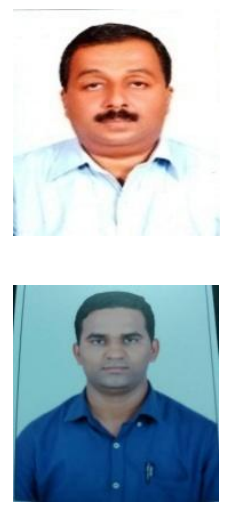

Mr. Z.S.PUNEKAR presently he is working as professor in civil engineering department of Secab Institute Of Engineering And Technology Vijaypur India.

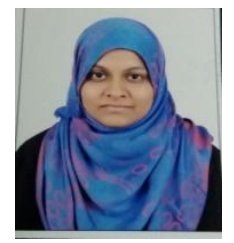

Mrs. ANJUM ALGUR presently She is working as Associate professor in civil engineering department of Secab Institute Of Engineering And Technology Vijaypur India.

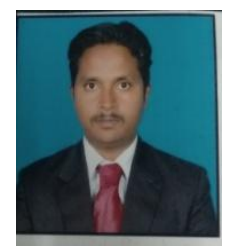

Mr. KUSHAPPA M K presently he is working as Assistant professor in civil engineering department of Secab Institute Of Engineering And Technology Vijaypur India. 